\title{
A TYPOLOGY OF FRENCH MARKETPLACES: LOOKING INTO A COLLABORATIVE FUTURE
}

\author{
Oihab Allal-Cherif \\ Grenoble Ecole de Management and LINC Lab \\ Europole, 12 rue Pierre Semard, BP127, 38003 Grenoble, FRANCE \\ IRIMA: Institut de Recherche et d'Innovation en Management des Achats \\ oihab.allal-cherif@grenoble-em.com \\ Dimitris G. Assimakopoulos \\ Grenoble Ecole de Management and LINC Lab \\ Europole, 12 rue Pierre Semard, BP127, 38003 Grenoble, FRANCE \\ dimitris.assimakopoulos@grenoble-em.com
}

\begin{abstract}
The deployment and use of electronic marketplaces contrary to expectations still remains marginal in the 'Francophone' business landscape. Even though several major business groups act as champions and invest in them, the vast majority of large and small companies remain wary of these digital intercompany platforms. Despite convincing arguments discussed in the scholarly, professional and trade literature, the credibility of marketplaces is constantly undermined in practice as they have to incessantly fend off rumours about bankruptcy in France and elsewhere. Moreover, the term 'marketplace' can cover a multitude of business relationships and it is currently difficult to compare offers and distinguish across a range of services. The purpose of this paper is therefore to put forward a typology, by identifying, analysing and classifying the about 225 Francophone marketplaces we found in the fall of 2007. The proposed typology enables us to (1) highlight their diversity and types of economic models that underpin their value chain (2) observe that the majority neglects certain high-added value services for which demand is great, and favours services which are hardly cost-effective and for which supply is much higher than demand, and (3) highlight future possible evolutions by examining the collaborative strategies few of these professional virtual communities have been making in the past few years.
\end{abstract}

\section{INTRODUCTION}

It seems quite surprising that electronic marketplaces are still struggling to hold sway over the digital networked economy. One would think that the savings vowed by these Internet enabled business platforms would attract hoards of clients eager to make both quick and long-lasting productivity gains. However, commercial success is scarce for the entrepreneurial contenders who embark on the marketplace adventure, and out of the thousands of start-ups that invested in this niche over the last decade or so, only a few hundred in the world actually survived the downturn in 2000. Their number is still dropping today in the aftermath of mergers and 
bankruptcies of the past few years. And yet, for almost 20 years, experts have agreed that the volume of Business to Business (B2B) commercial exchanges generated by electronic platforms would rise significantly and affect all industries (see, for example, Malone, Yates and Benjamin 1987, 1989).

From the outset, it is not easy to define to what extent companies would be welladvised to steer away or follow this digital hierarchization process. Moreover, given that about 80 percent of the marketplaces created in Europe since 2000 have disappeared, dubiousness reigns. One can still find, however, a countless amount of services whose added value can vary considerably. Marketplaces integrate functionalities that go far beyond the framework of procurement, which is the most common, but not the only domain of expertise. Instability, diversity and fragility do not often facilitate the choice of an e-business solution. Companies liable to use marketplaces need to have a better understanding of their landscape, but it seems almost impossible to obtain a clear vision in such a complex and unstable environment (Grey, Olavson and Shi, 2005). And yet, the stakes are high, because the rise of the Internet in inter-company business dealings has turned optimizing partnerships and customer / supplier management into an important and decisive competitive advantage. It is therefore paramount not to be outstretched by competitors in this domain. Even more so, since strategic positioning is often now built in a global context and the life cycles of products and technologies are becoming shorter, leaving decision-makers little room for hesitation. It seems timely therefore to address the following set of questions:

- Are marketplaces strictly tools for optimizing costs, or can they be used as strategic tools for collaborative project management, market analysis and intelligence? Or, put it differently, should marketplaces attach more importance in managing transactions, or harnessing information and enabling collaboration and networking as seen in few successful virtual professional communities?

- Are marketplaces tools for heightening competition, or means for encouraging collaboration among actors that would not otherwise seek to work together in developing new products or services?

- What is the future of marketplaces? Or, how can we distinguish those which really have a future, from those which are already jeopardized by economic models that are not viable?

To provide some answers to the questions above, we identified about 225 Francophone marketplaces in the fall of 2007 and listed their functionalities (AllalCherif, Assimakopoulos and Favier, 2008). This exploratory research yielded an analysis of the Francophone marketplaces within a typology matrix which addressed the type of relations that existed among a broad range of actors. The individual positioning of each of these marketplaces enabled us to observe the strategic positioning of marketplaces in France, and in the French speaking world, as well as speculate about the future of these marketplaces. But before we discuss some of our findings, in the next section we review three distinct views of marketplaces according to the scholarly and professional literature. Furthermore sections 3 and 4 respectively present our research methodology and discuss some of our main findings, including our typology of marketplaces in the Francophone business landscape. Finally, section 5 offers some concluding thoughts looking into a near 'collaborative' future. 


\section{THREE VIEWS OF MARKETPLACES}

Back in 2000, Philippe Nieuwbourg, President of the European Marketplace Association, defined marketplaces as 'virtual spaces for companies to conduct business' (Nieuwbourg and d'Hondt, 2000); Internet sites, where sellers and buyers come together, and make transactions for the purchase of products and services. At least, that is what marketplace managers hoped for, since they would make money easily on this type of activity by charging a commission on each completed transaction among a large number of sellers and buyers. For example, Consumer Packaged Goods, CPGMarket (www.cpgmarket.com) is a marketplace that federates purchases for several major agro-food groups (e.g., Danone, Henkel, Nestlé) from its 7900 suppliers. It completes a huge number of transactions, but this case is exceptional, in the sense that when the industrial giants decide that their transactions will only be made by means of their common marketplace, the suppliers have little choice but to follow suit. Yet an independent marketplace, which simply introduces itself as a new place for buying and selling, and whose only particularity is the fact that it is digital, would hardly be attractive enough to survive.

Commentators have also underlined that a marketplace can be defined in the broad sense of the term, as a site of informational exchange about supply and demand, to which the main actors of a given sector or field of activity subscribe' (Rechenmann, 2002). The term 'transaction' has disappeared from this definition: the main aim of marketplaces is therefore shifted from being essentially commercial, to be informational. The decision-makers who visit these marketplaces are, first and foremost, looking for information that will enable them to innovate -generate novel ideas thanks to new economic or technical opportunities that can be consulted on the site - or develop their company thanks to a better understanding of acquired or open market segments. Before aspiring to the title of exclusive purchasing platform of a given sector of activity, i.e. the transactional marketplace, the marketplace must firstly be informational, in other words, federate all of the actors of a professional virtual community and forge itself a solid reputation (Rechenmann, 2002).

The term 'marketplace' is an umbrella term encompassing a number of very different realities because it is used to qualify many forms of inter-company digital relations. These relations essentially exist between companies and their suppliers and range from the simple 'one-shot' purchase, in response to a very specific need, to a long-term partnership, with all associated co-developments, joint investments, projects related to new components, new products, or new technologies. But marketplaces can also facilitate collaboration between companies in competition, be it for buying or selling, or/and, in research and development projects. Marketplaces can therefore position themselves very differently depending on the market they focus on, the way they wish to be remunerated and the role they wish to play with respect to their members. The main advantages of these inter-organisational platforms stem from reducing transaction and coordination costs for all actors, facilitating the search for new suppliers, comparing offers more easily and more comprehensively, eliminating intermediaries, and benefiting from economies of scale. Marketplaces are hybrid organisations between the market itself, where Porter's five forces determine the transactional conditions, and hierarchy, where management sets the standards of acceptable quality, costs and deadlines. 
Marketplaces therefore question linear models for circulating goods and capital (Fisher, 1997) and favour the development of networked structures which encourage both competition and collaboration among companies. Even though, the main characteristic of marketplaces is to encourage the circulation of information, therefore to considerably increase the level of transparency within a market (Soh, Markus and Kim, 2006), a better understanding of these tools indicates that the real upheaval will reside in collaboration. Marketplaces constitute a potentially ideal way of coordinating the joint actions of several companies in accomplishing their projects, sharing strategic information and resources, or developing new products and innovative technologies.

Uncertain environments, asymmetry of information and the diverging interests of the marketplace providers and their members assimilate relations between operators, buyers and suppliers to that of an agency relationship (Brousseau, 1993). Such a relationship 'relies on contracts through which two types of organisations (buyers and suppliers) subscribe to the services of a third party (the operator) to accomplish, on their behalf, one or several tasks, in a given decisional domain'. Such a relationship often favours buyers who have the freedom to take initiative and leave suppliers with no choice but to become a member of certain marketplaces chosen for them. Often the founder of a marketplace, and thus its principal shareholder, is a buyer, as it is the case for example in Schneider / SourcingParts. Naturally, this threefold agency cooperation agreement seems skewed, since some interests are easier to be defended than others, and not all stakeholders share the same motivations for belonging to a marketplace. This inequality is undoubtedly one of the main reasons that underlie the unpopularity of marketplaces, because if all parties do not build such relationship based on mutual trust (Pavlou and Gefen, 2004), it is likely that such relationship is going to be under significant strain to deliver in the relatively short term. It may therefore seem meaningful to question such an agency relationship in order to balance out the benefits for each of the parties involved in a marketplace. This rebalancing is not going to take place without a radical change in the underlying economic model, which should no longer be based on cost reductions and optimal transaction management that disadvantages suppliers, but on the added value of a tactical, or even strategic partnership, as opposed to a purely operational one, with these same suppliers. Commentators (e.g., Hartman, 2002) systematically bring the 'cost' dimension of marketplaces to the forefront. However, corporate networks, with several people connecting to the same websites, demonstrate in practice that marketplaces also have a very prominent social dimension. Indeed the economic relations among individuals necessarily entail social relations, such as trust (or the lack of it), that can strongly influence the workings of business practices highlighting how economic action is embedded on social structures and networks (Granovetter 1985; Ratnasingam Pavlou and Gefen 2005, Assimakopoulos 2007).

\section{RESEARCH METHODOLOGY}

There already exist typologies of marketplaces, but they seldom take into account the type of market or products they deal in. These typologies can hence integrate tools which are not really marketplaces, but on-line e-commerce, auction or price 
comparison sites. Many terms are used in the academic literature to designate marketplaces, or other phenomena which are similar, yet different. It is difficult indeed to draw a distinction between 'electronic marketplace, electronic market, electronic trades, electronic exchange, electronic hubs, electronic platforms' (Hartmann, 2002). Moreover, increasing integration and convergence of tools make this already confusing situation even worse. For example, ERP systems increasingly integrate more marketplace functionalities, and the marketplaces are integrating more and more ERP functionalities. It is therefore becoming increasingly difficult to distinguish the specific services provided by marketplaces from those commonly offered by other tools. And yet, a number of expectations from companies, which are specific to purchasing and supplier management, come under heavy criticism. These companies would be ready to invest massively if the marketplaces could only offer real long-term solutions to their purchasing problems, not just 'cost killing' options, and news that is only interesting momentarily.

Our research is therefore exploratory in so far as it aims to build a typology of Francophone marketplaces and present a profile of the state of the art of these marketplaces, including services they offer. In the light of such typology we identify opportunities that could lead to the adoption of a different strategy for a better match with expectations of potential clients. In particular, our research followed a four step approach:

The first step consisted in reviewing scholarly and trade literature to draw up an initial list of the most well-known Francophone marketplaces and their principal functionalities. In parallel to this initial inventory, the study of existing marketplace typologies enabled us to determine the criteria by which we could clearly distinguish the composition of this group and its evolution. We shall see below that certain marketplaces are purely operational tools, while others are tactical, others are strategic, and, depending on the case, they offer a broad range of services.

The second step was an Internet search, using search engines to find specialised forums, newsletters and new marketplaces in order to complete the initial list. This was followed by a telephone or mail contact in order to gather a certain amount of detailed information about the functionalities available on each platform. This firsthand information enabled us to build a matrix that associates each of the 225 identified marketplaces to a set of tools offered to its clients.

The third step was based on the previous two and resulted in the drawing of a cognitive map for positioning the functions and service providers along two axes: a horizontal axis measuring the duration of a relationship between the members of a marketplace, and a vertical axis that shows the degree of cooperation between each of the stakeholders. This positioning then led us to structure our typology in four types of services that determine four types of marketplace: e-sourcing, eprocurement, business intelligence and collaborative commerce, with the possibility that one marketplace can cover more than one type of service, or evolve from one type to another.

Finally, the fourth step consisted in putting together a matrix, where the lines show the 225 Francophone marketplaces, and the columns show their functionalities, and precise nature of the services proposed by these marketplaces according to our typology. We could subsequently understand the current situation and draw certain conclusions about the potential and future of these marketplaces. 


\section{MAIN FINDINGS}

The first challenge we encountered in trying to identify and classify all Francophone marketplaces, was a problem of definition, as we've already pointed out above. We accepted a broad working definition that marketplaces can include all the web sites which establish relations of collaboration or competition among companies within the same market. We therefore had sites similar to eBay, a site that supports a great number of companies also in France, claiming the status of marketplace. We also had to go through marketplace referencing directories and the trade press to target all sites that fitted our definition. We completed this initial list with marketplaces selected directly from the Internet, by means of an Internet search and with some additional unreferenced or unregistered marketplaces that had been featured in press articles, or consulting companies' surveys. If these marketplaces could be counted by the hundreds in 2000, it is difficult to list more than a few hundred in France today, all industries included. The last hurdle consisted in comparing their web sites, which despite many points in common, addressed different markets - from the agro-food industry to automotive, to computers, to services, from small start-ups to the subsidiary of one, or several major industrial groups - following different strategies - some buyer-oriented, others supplier-oriented, and others claiming to be independent. By choosing criteria related to the types of relations allowed by the marketplace, as opposed to those related to sectors, or volumes, we focused on the essence of marketplaces, on their 'raison d'être', on what makes them not only attractive to their members, but encourages the loyalty of the latter. In the process we had to identify all types of services likely to be offered by a marketplace and sort them into four broad categories according to the services provided: e-sourcing, eprocurement, business intelligence and collaborative commerce, see Figures 1 and 2.

We define 'e-sourcing' as the search, via Internet based information systems, and over a relatively short period of time, i.e. a few days up to a few weeks, for answers to a commercial inquiry with a view to obtaining the lowest cost and near-immediate cost-effectiveness. It therefore involves finding the best source to respond to a need expressed by a company. This search is accompanied by 'digital negotiations' enabled by new tools such as e-RFIs (electronic Request For Information), forms that allow one to progressively select the top suppliers likely to win a tender, e-RFPs (electronic Request For Proposal), which enable one to finely compare offers, and eRFQs (electronic Request for Quote/Quotation) which determine the final decision. The e-sourcing process often ends in reverse auctioning to mechanically lower prices and decide between the final suppliers who have passed through all of the prior screening processes. E-sourcing does not really integrate the notion of partnership or of building a long-lasting collaboration between the buyer and the supplier to which it applies. There is therefore an intense and radical sense of competition, the purpose of which is to respond to a punctual need while optimising certain criteria, without considering the quality of the relationship with the supplier in question. Companies, such as HP France or Caterpillar France, regularly revert to auctioning in order to acquire batches of components, or certain volumes of raw materials, needed to manufacture their products. These auctions are organized sporadically with no intention whatsoever of developing further relations with selected suppliers once a transaction has been completed. 
'e-procurement' consists in establishing longer term commercial relations compared to 'e-sourcing' between a company and its suppliers thanks to ICT, i.e., it enables the company to structure, record, analyse and optimize the terms and conditions of the products and services provided by these suppliers over a period of a year or so. Suppliers are thus subjected to financial, industrial and technological audits in order to receive an approval needed to belong to a company's partners for a substantial period of time. They can thus benefit from semester or annual purchasing commitments in terms of production volumes from buyers who sign framework contracts which set levels of price, quantity, and above all quality, with penalties in the event of the non-respect of these conditions. The core functionalities of eprocurement systems consist in the consultation of e-catalogues and the issuing of on-line purchase orders. The possibility of saving invoices and analysing data collected by computer tools is an effective means of evolving from the reaction to a "one-off need", to anticipating such need and the implementation of a purchasing strategy that can be examined in more detail through 'business intelligence'. For example, out of the 110 worldwide Thomson sites, the e-procurement application, Hubwoo, is the second most widely-used application after the mail. Managing 1,8 billion euros of purchases in 2004 and roughly 10000 orders, the use of a purchasing platform generates considerable returns on investment. The example is even more evident with EDF (Electricté de France - the French Electricity company) and its 1800 agencies in France. e-procurement tools enable EDF to standardize the purchasing processes between the company's agencies and each partner and realize economies of scale. Moreover, given that the EDF agencies know which suppliers they use regularly, they have reduced considerably the number of suppliers in the past few years, and have enabled EDF to focus on those offerings with the best business terms.

'Business intelligence' involves setting up standardisation, globalisation and anticipation solutions with key suppliers, so that a purchasing department can function seamlessly in terms of time and space. Indeed, purchase benchmarking allows the circulation of best practices between countries or continents and between different services. The partnership between buyers and suppliers is particularly close and can involve technological transfers, collaboration on innovative research projects, and support designed to optimize the performance and cost-effectiveness of suppliers. The intervention of consultants or auditing agencies also allows the creation of purchasing procedure certifications. Clients and suppliers are closely interconnected at operational and logistic levels, where manufacturing orders are tracked from the factory to their point of reception. Loyalty is rather strong with these suppliers, who are deeply committed to the success of their client, with whom they share the same risks. For example, the Schneider group, with its solution provider SourcingParts, co-developed a purchasing platform which brings together the functionalities of 'e-sourcing' and 'e-procurement', but more importantly, of 'business intelligence'. The project was implemented to respond to the needs of a large multi-national group for which standardizing the tendering process was fundamental. But the need was also anticipatory: Schneider wished to have the capacity to analyse each of its 4 key markets and 58 purchasing segments in order to optimize the management of its purchase orders, procurement and stocks. Defining performance indicators for the purchasing service per market, segment, country, 
zone or buyer enables a progressive and continuous improvement not only of cost control, but also of quality, deadlines, technological innovations and purchasing projects.

'Collaborative commerce' is still in its early days in several sectors of the knowledge economy. And yet some companies have begun to develop and sustain cooperation over the mid-to-long term. Collaborative development and co-design consist, for one or several buyers and for one or several suppliers, in sharing resources in terms of knowledge, know-how, equipment or finances in order to create a new product or a new technology. Integrating suppliers into the innovation process offers considerable advantages as for example creating synergies and sharing the same final objectives. For example in the automotive industry, collaborative commerce among partners, who work on successive levels of the value chain, is particularly efficient in the co-design of technical products such as automobile vehicles. Peugeot is one of the few companies in France to have invested massively in this domain in order to develop its own platform, since the potential, in terms of generating competitive advantage, is significant. When we look at the strategic positioning of these marketplaces, we observe that they are concentrated in the 'e-sourcing' quadrangle, and the further we move away from this quadrangle, the fewer there are. Notwithstanding this finding, it is the functionalities of business intelligence and collaborative commerce that are the most popular, and bring most added-value. However they do require greater expertise and trust for companies to join in. Demand is high and even though the investments needed may be significant, there is little supply and great demand for such services.

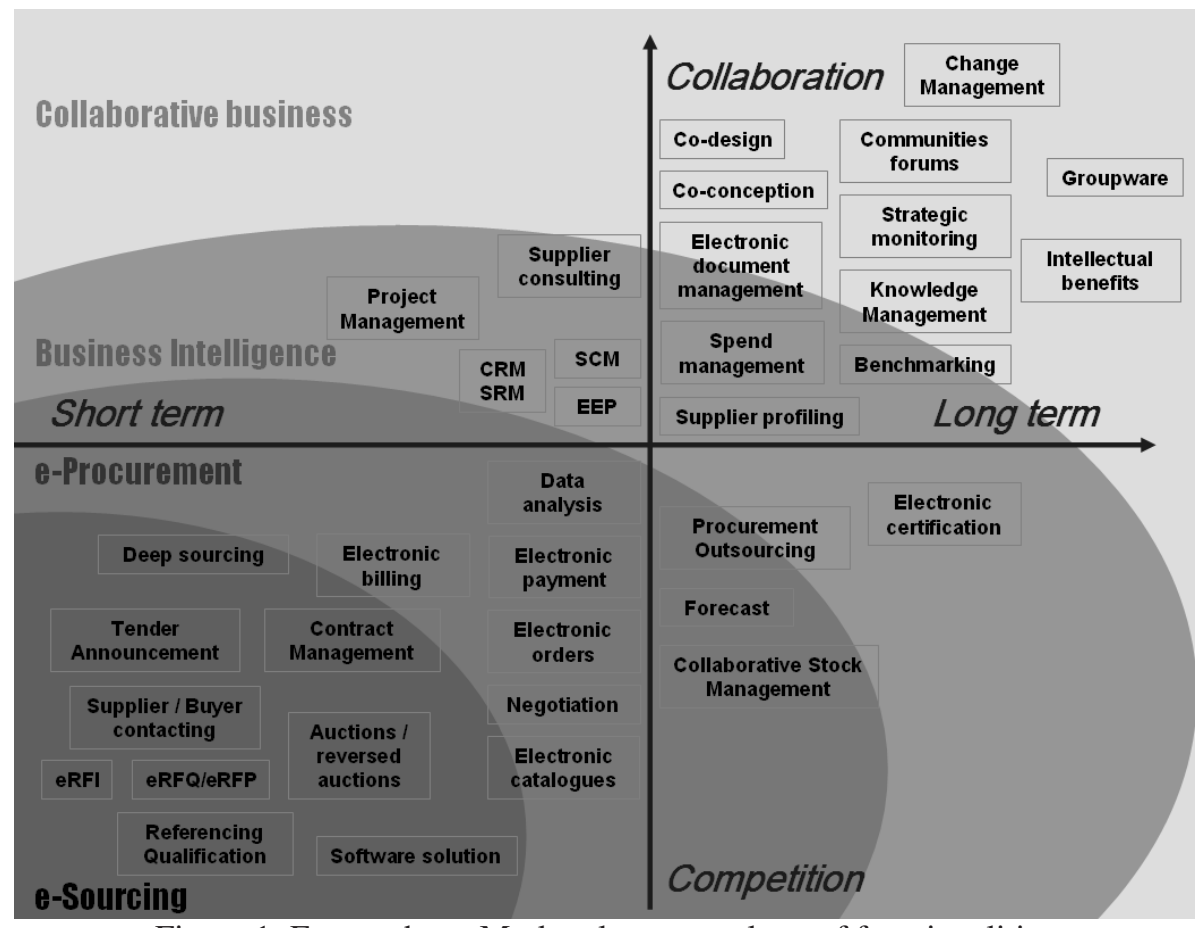

Figure 1: Francophone Marketplaces: typology of functionalities 


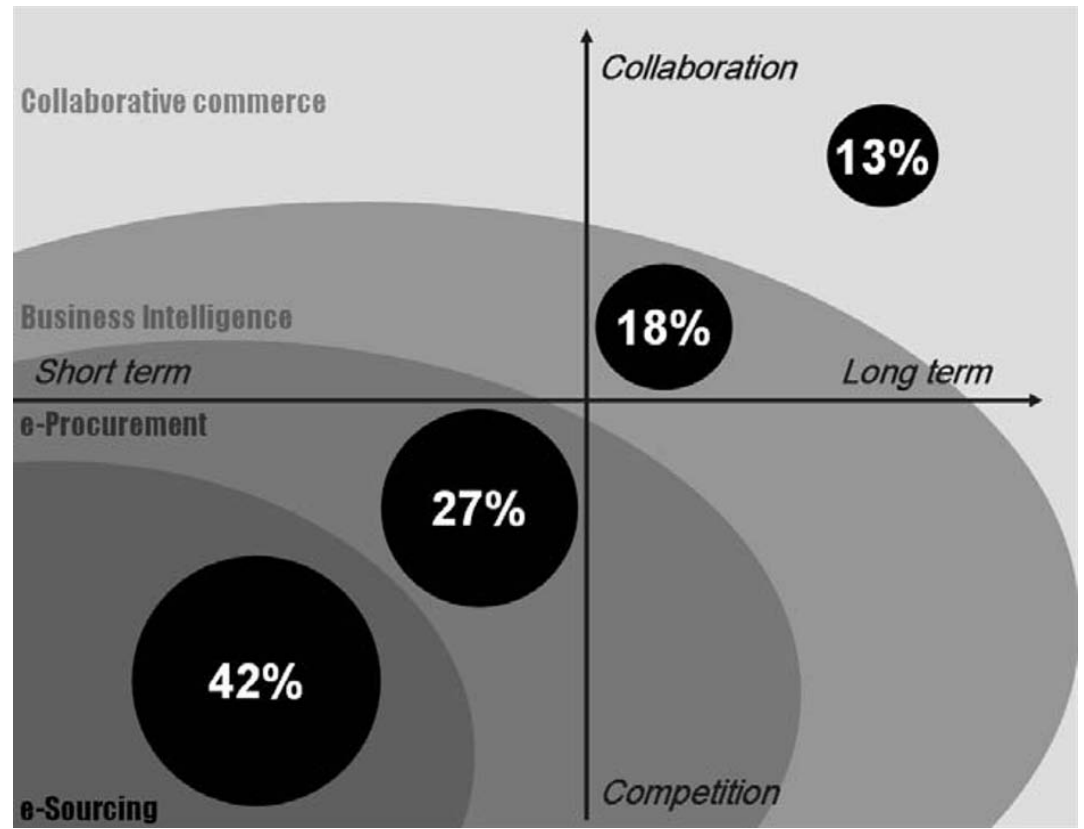

Figure 2: Percentages of the 225 marketplaces according to the 4 types (AllalCherif, 2007)

\section{CONCLUSION}

The analysis the state of the art of marketplaces in France in the fall of 2007 leads us to the conclusion that there is a split between the expectations of companies and the markets their embedded in, and what generally most marketplace providers offer to their clients. Indeed, the majority of marketplaces compete with each other on services related to e-sourcing and e-procurement. Their number (155) and concentration (69\%) is high in this quadrangle (see, Figure 2), though they have difficulty when positioning in this quadrangle to being cost-effective and above all they neglect high added value services such us joint project management, product co-design, anticipative purchase analysis and other collaborative services valuable to managers. Having identified this, we can also underline that the concentration of marketplaces leads them to merge or create strategic alliances in order to provide a more comprehensive range of collaborative services and offer solutions that cover all aspects of purchasing and not just the notion of cost control. The choice of a new economic model, which takes into account social relations, such as trust, involved in transactions, would therefore be paramount in making marketplaces more attractive and cost-effective for enabling business intelligence and collaborative commerce. They would thus become true informational platforms and professional virtual communities building tools, federating their resources to reach aims that would otherwise be unattainable without the use of such inter-organisational Internet based systems. 


\section{REFERENCES}

1. Allal-Cherif O. (2007), An economic model for electronic marketplaces, $\mathrm{PhD}$ thesis in Management Sciences, University of Grenoble 2, UPMF, may 2007.

2. Allal-Cherif O., Assimakopoulos, D., Favier., M. (2008), A Business Model for French Marketplaces, paper to be presented in the International Conference on Information Systems (ICIS'08, http://www.icis2008.org/), Paris, December 14-17, 2008.

3. Assimakopoulos, D. (2007), Technological Communities and Networks: Triggers and Drivers for Innovation, Routledge, London and New York.

4. Bensaou M. (1999), "Portfolios of buyer-supplier relationships", Sloan Management Review, Summer, pp. 35-44.

5. Brousseau E. (1993), L'économie des contrats, Technologies de l'information et coordination interentreprises, Paris: PUF.

6. Büyüközkan G. (2004), “A success index to evaluate e-Marketplaces”, Production Planning \& Control, Oct2004, Vol. 15 Issue 7, pp. 761-774.

7. Choi Y. J., Suh C. S. (2005), "The death of physical distance: An economic analysis of the emergence of electronic marketplaces", Papers in Regional Science, 84(4), pp. 597-614.

8. Driedonks C., Gregor S., Wassenaar A., Van Heck E. (2005), "Economic and Social Analysis of the Adoption of B2B Electronic Marketplaces: A Case Study in the Australian Beef Industry", International Journal of Electronic Commerce, 9(3), pp. 49-72.

9. Fisher, M.L. (1997), "What is the right supply chain for your products?", Harvard Business Review, March, pp. 105-116.

10. Gengatharen D., Standing C., Burn J. (2005), "Government-supported Community Portal Regional emarketplaces for SMEs: Evidence to Support a Staged Approach”, Electronic Markets, Dec2005, Vol. 15 Issue 4, pp. 405-417.

11. Granovetter M. (1985), "Economic Action and Social Structure: The Problem of Embeddedness", American Journal of Sociology, 91(3), November 1985, pp. 481-510.

12. Grey W., Olavson T., Shi D. (2005), "The role of e-marketplaces in relationship-based supply chains: A survey", IBM Systems Journal, Vol. 44 Issue 1, pp. 109-123.

13. Hartmann E. (2002), Successful introduction of B2B Projects, an Inter-Organizational relationship Perspective with an Empirical Analysis of the Chemical Industry in Germany, von der Fakultät VIII Wirtschaft und Management der Technischen Universität Berlin zur Erlangung des akademischen Grades Doktor der Ingenieurwissenschaften.

14. Jai-Yeol Son, Tu L., Benbasat, I. (2006), "A descriptive content analysis of trust-building measures in B2Belectronic marketplaces", Communications of AIS, 2006, Vol. 2006 Issue 18, pp. 2-51.

15. Malone, T W, and J Yates and R I Benjamin (1987), «Electronic Markets and Electronic Hierarchies: Effects of Information Technology and Market Structure and Corporate Strategies», Communications of the ACM, 30:6 June 1987, pp. 484-497.

16. Malone, T W, and J Yates and R I Benjamin (1989), "The Logic of Electronic Markets", Harvard Business Review, May-June 1989, pp. 166-170.

17. Mirza B. M., Vipul G., Richard C. C. (2004), "E-marketplaces and the future of supply chain management: opportunities and challenges", Business Process Management Journal, Vol. 10 Issue 3, pp. 325-335.

18. Nieuwbourg P. et d'Hondt H. (2000) - Places de marché sur Internet, Nouvelles règles pour le commerce du XXIéme siècle, Editions BNTP 2000.

19. O'Reilly P., Finnegan P. (2005), "Performance in Electronic Marketplaces: Theory in Practice", Electronic Markets, Feb2005, Vol. 15 Issue 1, pp. 23-37.

20. Pavlou P., Gefen D. (2004), "Building Effective Online Marketplaces with Institution-Based Trust", Information Systems Research, Mar2004, Vol. 15 Issue 1, pp. 37-59.

21. Ratnasingam P., Gefen D., Pavlou P. A. (2005), "The Role of Facilitating Conditions and Institutional Trust in Electronic Marketplaces", Journal of Electronic Commerce in Organizations, Jul-Sep2005, Vol. 3 Issue 3, pp. 69-82.

22. Sharifi H., Kehoe D. F., Hopkins J. (2006), "A classification and selection model of e-marketplaces for better alignment of supply chains», Journal of Enterprise Information Management, Sep2006, Vol. 19 Issue 5, pp. 483-503.

23. Shaw M., (2000), "Electronic Commerce: State of the Art", in Shaw M., Blanning R., Strader T., Whinston A., Handbook on Electronic Commerce, Springer, Berlin, pp. 3-24. 